\title{
Education as a Strategy for Sustainability in the 21st Century: Teachers as Creators of Educational Change
}

\author{
Gabriela Scartascini Spadaro, PhD \\ María Guadalupe Talavera Curiel, M.A. \\ Vilma Zoraida Rodríguez Melchor, M.A. \\ University of Guadalajara, Mexico
}

doi: 10.19044/ejes.v4no4a5 URL:http://dx.doi.org/10.19044/ejes.v4no4a5

\begin{abstract}
We are part of a globalized world that is reflected in problems associated with the development of the various dimensions of human endeavor. Intellectuals and scientists, who explain the complexity of the $21 \mathrm{st}$ century, emphasized on the fact that human beings swing between a strong consumer tendency and the capture of immediacy. There is a need for an ideal interconnected to values and ongoing actions tending towards sustainability. This is with the aim of legitimizing the various dimensions of human development where education forms a determining part. Taking into account the mentioned context, this work reflects on the work of the teacher, a key piece in the formation of students and institutional view. The literature will be reviewed and practical strategies will be proposed and focused on strengthening human understanding in global complexity. This is because teachers are expected to become the strategists that avert the great challenges faced by education in the 21 st century global society.
\end{abstract}

Keywords: Education, Sustainability, Teaching practice, Social transitions.

\section{Introduction}

In a look that is positioned beyond the first group of socialization such as the family, this proposal reflects on teaching practice. However, this is because teachers are the ones who have the power to influence, on a daily basis and for hours, the knowledge and the reactions of the school community, against the daily context, and inside and outside the educational institution.

In the last decades, they have focused on bringing to the stage of dialogue and citizen debate issues such as exclusion, harassment, and discrimination. Issues that are installed under the name of "bullying", reflect actions of rejection against the "other" and its consequence has a negative impact on classroom environment. 
For this reason, it is worth analyzing, when reflecting on education, what are the concrete strategies which work to achieve a view towards sustainability - understood as welfare and quality of life - and are they sufficient to cover the long term? Or will it simply depend on the particular and individual look of each teacher in the classroom?

Since it is beyond general policies and regulations regarding the rights that each human being possesses, there are conditions that do not allow the coexistence with inclusion and respect that each human being needs to develop fully. Consequently, educational policy strategies require a concrete and real intervention practice that model the particularities and guide towards the solidarity and the well-being of students. This therefore is aimed at making learning to be integral and sustainable. However, while the time comes for institutions to establish the policies that are urgent today, teachers should be ahead of the times because the work day requires it.

Education is a strategy that goes beyond knowledge in school subjects. Therefore, it is fundamental to maintain the updated professional development of teachers in the different dimensions of human development. Focusing on broadening the circle of action aimed at dialogue about one's own teaching practice and the context in which it develops, it is a debate that requires contexts that recover it for its update based on the benefit of our globalized educational community.

The greatest challenge is faced by teachers and professors as they are the ones who deal directly with students in the classrooms. These students have different mindset and perception based on how they grew up. Teachers are the ones who interact from Monday to Friday for several hours, with an average of 30 students which is equivalent to 30 families with different backgrounds and problems.

Even when it is difficult to break the siege of the first group of socialization which is the family, the teacher plays a significant role in bringing transformation in the society beginning from his or her own classroom.

\section{Literature Review \\ What is Quality in Education?}

In the $21^{\text {st }}$ century, competencies refers to the need to cover all areas of human development in terms of social, family, personal and in the case of higher education, insertion into the labor world. Therefore, in addition to reading-writing and logic-mathematics, skills such as critical thinking, creativity, collaboration, computer thinking, and problem solving stand out.

Under the main premise of continuous and lifelong learning, the aim is to achieve equitable and inclusive education. This is both in terms of 
intercultural dialogue and gender perspective, as well as the relationship with minorities generated by race, religion, migration, and sexual preference.

When there is a perception that there are "others", embodied in different cultures and customs associated with unique processes of historical construction, at least two are the paths to take: understanding or rejection, both with their nuances. If a respectful interaction is achieved in the school environment, a fact as basic as respect for human rights will have regained its initial vision.

The daily work in the teaching of values, attitudes, and aptitudes towards sustainability will be reflected in the classroom and, above all, during recess time which is a symbol of freedom and interaction between peers with absence of constant adult supervision.

Preparing for the transitions that happen in these times is the ideal. However, in school practice, there will always be winding and paved paths to go through.

\section{Every Day towards Sustainability}

In 1987, the United Nations Organization presented the report of the World Commission on Environment and Development, entitled "Our Common Future". Consequently, this is now known as the "Brundtland Report" in honor of its president, Gro Harlem Brundtland. It gives the world the definition of sustainable development for which "humanity has the ability to make sure that it meets the needs of the present without compromising the ability of future generations to meet their own needs" (UN, 1987). The document highlights the close relationship between poverty and its consequences: "Poverty is not only an evil in itself, but sustainable development requires meeting the basic needs of all and extending to the opportunity to fulfill their aspirations for a better life. The world in which poverty is endemic will always be prone to ecological and other catastrophes" (UN, 1987: 16).

The initial look at the need for sustainability applicable to development was initially associated with ecological issues as well as the control of world hunger and poverty. This is in addition to economic growth between first world countries and the rest of the world.

Over the years, the concept has expanded its horizons. Currently and based on the Sustainable Development Objectives promoted by the UN from 2015, and in the face of Agenda 2030, sustainability must be a priority in everyday life and in different areas of social work, whether in health, education, labor market, industrial world, institutional spaces, economy, and issues such as gender equality, reduction of inequalities, terrestrial ecosystems and underwater life, climate change, and drinking water for all. 
Peace, justice, and well-being in planetary life are terms of an irrevocable negotiation towards the next years. Hence, they should at least be reflected in the statements signed by the so-called member countries.

Furthermore, there are 17 Sustainable Development Goals (SDGs). The SDG related to Education aims to "ensure inclusive and quality education for all and promote lifelong learning" (UN, 2015).

Inclusion and equality are the dominant concepts in policies that should guide the educational dimension. Minorities, including people with disabilities, indigenous peoples, refugees, and migrants as well as rural communities, are the cornerstone on which to base strategies for sustainability.

One of the goals by 2030 is to ensure that all learners acquire the knowledge and skills needed to promote sustainable development. Through education, students will be able to think about sustainable lifestyles, human rights, gender equality, promotion of a culture of peace and non-violence, global citizenship and appreciation of cultural diversity, and appreciation of the contribution of culture towards sustainable development (UN, 2015).

According to this SDG, a key point is that the daily purpose in the classroom will consist of generating strategies that will turn students into representatives and promoters of actions tending towards sustainability, in a school and family environment. As a result, it is essential to look into the concrete meaning of a culture of peace, non-violence, appreciation of diversity and the culture of "No bullying inside and outside of the classroom".

Therefore, what steps could be taken in the face of a situation in which, according to social scientists, immediate violence, insecurity, and difficulty in dialogue prevails?

\section{$21^{\text {st }}$ Century Societies}

Edgar Morin, Zigmunt Bauman, Noam Chomsky and Boaventura De Sousa Santos, each from different contexts, agree that the impact of actions and policies has a direct or indirect impact on the global order.

Zigmunt Bauman, Polish sociologist and father of the paradigm of "Liquid Modernity", raises the need to learn to live in a world saturated with information. However, any delay is a stigma of inferiority, and success depends on achieving instant gratifications without any delay. He stated that, in liquid societies, the prospect of thinking about something that lasts a lifetime is disdained, since things and bonds are expected to last for a time and then be discarded. So, at the end, everything is scheduled, even obsolescence (2007).

As for the tendency of education, the objectives are placed in the achievement of products and not as an ongoing process of learning, for which "we must learn the even more difficult art of preparing the new generations to live in such a world" (Bauman, 2007: 41). 
Chomsky (2001) points out that, even in the 21st century, the school, as an institution, exercises a control system that gives prevalence of obedience towards power structures. Hence, a reason for (un) education arises as it does not strengthen the critical and democratic reflection of students.

Boaventura De Sousa Santos (2015) enunciates, through the "ecology of knowledge", an educational proposal that is associated with action research, as a way of deepening the social changes. This researcher highlights that teachers are trapped in a labyrinth between scientific knowledge and the discourses of everyday life.

Consequently, the crossroads meet between transiting dialogues or remains indifferent or even elusive to listen to complexity through their various sounds proposed by the ecology of knowledge. This is regarded as "a set of practices that promote a new active coexistence of knowledge with the assumption that all of them, including scientific knowledge, can be enriched in this dialogue"(Santos, 2015, p 129).

The complexity of the current situation must be worked together with the components that make up the universal whole, regardless of the human development dimension to be addressed. Therefore, in the case of education in particular, knowledge must be integrated to strengthen the comprehensive training of students from the earliest age.

This active intervention in the classroom, based on the fulfillment of the Sustainable Development Goals, is the one that will allow the cultural encounters, the dialogue of knowledge, and tenacity in the continuous search for knowledge. This is because as a butterfly effect, a little initial change in any part of the world will have an unimaginable and unpredictable impact on the planetary system.

\section{Theoretical Perspectives \\ Education in Complex Societies}

Edgar Morin highlights that the figure of the teacher is decisive for the consolidation of an ideal model of education since the teacher "must be the orchestra director who observes the flow of knowledge and solves students' doubts" (2014). Teachers are the holders of a social mission since they are educators of public opinion and future citizens. They need to be aware of the mission. Therefore, it is vital that they articulate their basic academic knowledge with other disciplines to dialogue with other fields of knowledge and, thus, be able to reflect with the students about the complexity of the current world, its past, and the future that they should build.

In this context, educators require extensive general cultural training and knowledge of the major issues surrounding our century in terms of religious and racial conflicts, uncertainty and possible projections in the world of politics and economics. Under this perspective, their strategy will be to 
reflect on human understanding since "the great problem of humanity is that we are all identical and different and we need to deal with those two ideas that are not compatible" (Morin, 2014).

In the school curriculum in particular, fragmented education through the disciplines, which are presented by subjects, leads to a reductionism contrary to the understanding of the complexity of reality. This therefore is articulated in all dimensions of human events. The strategy is to combine reason and rational control with emotion and passion.

Edgar Morin argues that there is a disarticulation between the fragmented knowledge of disciplines and the multidimensional and transnational realities of the Planetary Age whose essential problems are "never fragmented and global problems are each more essential" $(2002,13)$.

The complexity of our lives as a species requires continuous analysis and reflective processes that must be carried out by teachers in order to be able to transmit them into the school environment. This is an ideal space to explain the processes by which the problems of life, environment, violence, migration or poverty are shared globally since "Every person who takes on educational responsibilities must be ready to go to the forward posts of uncertainty in our times" (Morin, 1999: 3).

It is crucial that each human member in the school community has the ability to achieve an individual look that responds to rules in particular societies and as a member of a larger species: human beings. Teachers are the strategists to become a citizen of the Earth, with ethics and defender of democratic ideals and with a permanent self-examination (Morin, 2011: 262). This would help them to become aware of their own attitudes and aptitudes to understand others, respect and function positively as supportive members of a school community since "Ethics must take shape in people's minds through awareness that a human being is at one and the same time an individual, a member of a society, a member of a species (...) All truly human development must include joint development of individual autonomy, community participation, and awareness of belonging to the human species" (Morin, 1999:4).

Ethics and sustainability are concepts closely linked to the theory of complexity which is completed when the theory is applied in a concrete project in solidarity and visible benefit of a community or social group for which work is based on "action research".

Another concept that is articulated in order to give priority to dialogue and human understanding is that of moral culture. In the same definition, it was pointed out that it focuses on the integral analysis of the contexts and the consequent practical application of the decisions taken.

Therefore, in terms of education, moral culture should be emphasized as a process aimed at sustainability. Schools are currently too busy with 
standardized testing and in preparing students to meet the standards that they overlook, and also the moral culture that children need to strive in life.

According to Puig (2011), "Moral culture is what is done in the institution. It is the set of educational practices that forms the complex system of dispositions, actions, and activities of the educational institution. We will argue that moral culture is a global quality of complex institutions resulting from its system of educational practices and the world of values it creates"(p.6).

When moral culture does not hold up, external social problems filter into educational institutions and produce turmoil in teaching-learning strategies and processes. Moreover, it deepens the problem associated with the hidden curriculum of each teacher.

In traditional pedagogy, moral culture was based on discipline. At present, these set of practices that supports moral culture, produces a synthesis effect that is constructed on the citizen culture with affection, reflection, and action are the three major vectors used by teachers to operate the practices to produce transformations in apprentices. All of these practices are done through dialogues and by listening to each other.

Probably one of the best ways of acquiring virtues is by participating with peers and with the help of an adult in a practice that expresses values. When a class works for projects, what they do in common, the "experiences of reflection and the emotions that live are recording virtuous habits in the character of each participant student"(p.9).

One of the issues that many times schools and classroom teachers fail to acknowledge is bullying among children. Many teachers believe that bullying is a normal part of childhood and they do not do anything about it.

However, the notion children have is that it is acceptable to step on each other, and the targets of bullies learn a helpless attitude towards those in power. Consequently, it is important that schools acknowledge the effects of bullying and do something about it. At the same time, teachers have to deal with this issue as well as any other issues that empower a student to feel superior over others.

Self-esteem should be encouraged in the classroom every day, to let students know that school is a pleasant place, where they can find people that care for them and respect them for who they are. Children learn their prejudices from their families and take them to school. In school, their prejudices are reinforced by teachers, classmates, staff, and the society in general.

Therefore, it should be the school's responsibility to teach students moral culture to break the cycle of intolerant behavior and injustice. Activities that call for multiculturalism in which students can learn from each other and value each other's differences and similarities should be promoted every day. 
By creating an equitable classroom, teachers would be teaching students to stand up for themselves whenever they face injustice and to join those who share the same beliefs to take action. Children would then grow up to be good human beings that care for the needs of others and would become the good citizens that every nation needs.

\section{Strategies for Creating an Equitable Classroom}

Teachers can use affective activities in the classroom. Affective activities will help students reduce anxiety and feel more comfortable in class interactions. According to Amato (2003), affective activities in the classroom "help students reach an understanding of those beliefs and behaviors that give meaning to their lives" (p. 295). Furthermore, these activities provide interactions in the target language and, at the same time, bring students closer together.

Those who feel less assertive, embarrassed, or intimidated in class can gain confidence with these activities and feel free to participate and share with the whole class.

It is important that at the beginning of the course, students and teachers should get to know each other. It is scary to participate in a class with members that you know nothing about. One activity that can be implemented at the beginning of the course is "find someone who." In this activity, students mingle around the room to find a person who meets the criteria specified in the handout and ask the person to sign his or her name. This helps break the ice and, at the same time, students get to know more about each other.

Another activity for the first class is learning each other's names by having the second student repeat the first student's name and have a third repeat the first and second student's name and so on. Later, students can interview one another before introducing the new friend to the class. If this type of activities continues as the course progresses, students will feel more comfortable in sharing their values and cultures. Therefore, this will be seen as a learning experience for everybody as they will learn to respect and value each other's differences and similarities. By carrying out these activities on a regular basis, it will allow dialogue on common themes that have a significant impact on the reality of the classroom as well as on the extracurricular space, whether at the family level or that are reflected in the media.

In addition, to foster multiculturalism, the "culture bag" or "me bag" can be implemented on a daily basis. Here, every class one student brings a paper bag decorated to represent what students like or consider important in their lives and cultures. Inside the bag, students place five objects that symbolize who they are, what they value, what they like, and what defines them as a person. This requires a lot of self-reflection and creativity in order to represent identity with small concrete objects that can be placed inside a 
bag. One student begins the class by showing and talking about each object. This activity fosters an attitude of pride in oneself and respect for others as they get to know each other, find shared similarities, and value the differences that make them unique.

It is the teacher's job to create a comfortable and non-threatening learning environment where all students feel safe to share their views. Furthermore, the teacher has to ensure that everybody is represented in the classroom. The classroom must display the work of all students. Students can bring pictures of the things they value and have their own spot on a wall or bulletin board where everybody can see. Students can then discuss why they chose to display that particular object.

Teaching by tapping on multiple intelligences is also beneficial to create a positive classroom environment. Using this strategy will promote more participation in the classroom since the lesson may be aimed to someone with a different learning style. Adding music, games, puzzles, role play, drama, and debates can trigger the excitement and motivation of students to participate more in class.

Different grouping arrangements must take place during instruction to give learners the opportunity to feel more comfortable and speak freely. Christison (1995) describes classroom grouping arrangements as: restructuring/mixers, one centered, unified centered, dyad, small group and large group.

Subsequently, these six strategies for seating arrangements must take place on a regular basis to give all students an opportunity to learn from each other and to stay away from the traditional teacher center classroom. Classroom interaction can be enriched by using different collaborative groups that allow for cooperative learning.

Error correction needs to take place subtlety in language classes. Many fear being interrupted and if the interruption is to let them know about their errors in the target language, students will feel anxious, intimidated, and will eventually refrain from participating. Richard Amato (2003) cites research done in the area of error correction that shows that "increased direct error correction does not lead to greater accuracy in the target language" (pp. 5657). Therefore, if error correction is to take place in the classroom, it should be done in the form of negative evidence and recast.

Teachers need to make an effort in making sure that all students have an opportunity to participate. In a whole class grouping, this can be achieved by the use of wooden popsicle sticks with the names of students in the class. Even shy students will participate when their name is called. The attention span of students increases when they know they might be asked to participate. This assures everybody a fair chance to participate. 
Teachers also need to be aware of their action zone. The action zone, according to Richards and Lockhart (1994), is the teachers' interaction with only a few students in the class. "An action zone is indicated by: those students with whom the teacher regularly enters into eye contact; those students to whom the teacher addresses questions, and those students who are nominated to take an active part in the lesson" (p. 139).

Once teachers are aware of their action zone, they can move around the room or have different areas in the room where they deliver instruction as opposed to the traditional teacher controlled classroom.

It is important to provide a silent period before students are ready to answer questions. One activity that can be implemented in large and small groups is having a talking piece. Here, students sit in a circle facing each other and can speak only when they hold the talking piece.

Implementing these ideas leads to greater participation from all students and a positive and respectful environment where everyone is welcome and valued because we need to learn how to live together in the $21 \mathrm{st}$ century.

\section{Conclusion}

We live in a system that swings between what is fragmented and unchanging. This displacement is also perceived in education, between the disciplinary and a contextual reality interconnected worldwide.

We are guided by the indications that govern international treaties and the counterpoint of the weight of the media and the dominant economic emporiums. This fact makes it difficult to articulate an educational work towards sustainability. Even so, the path is linked to essential meanings that emphasize the inherent value of teaching and its mission for educating with quality according to the needs of each time period.

In the XXI century, acting in favor of inclusion is found in the platforms of mission and vision of institutions, as well as in curriculum objectives. It is well known that one should not discriminate, harass, generate violence - symbolic or physical - to make fun of others; at least, that is what is proclaimed from school textbooks and at parent meetings.

In every country, community, and society, adults are the ones who must be informed about everyday events and the processes that have led to a period of time. This is in a bid to have a personal reading with answers to stand firmly in one's personal life and everyday work. Information and communication technologies (ICTs) can be valid tools in the process of being citizens of the world or social illiterates. Teachers are part of the social group that must educate in the complexity of the present, thinking about the future.

In order to talk about sustainability, it is imperative for institutions to carry out work with teachers to guide them, culturally, technologically and 
psychologically, towards a territory in which they can, by themselves, take an active look of respect for diversity. In the event that their first reaction is rejection, more tools to modify that perspective must be provided in order to face the challenges of the twenty-first century.

Thus, there is the need to implement a policy of responsibility in citizen education in each institution. This is done as a committed artificer with a work whose profile and strategies articulate sustainability, diversity, and interculturality. Furthermore, the teachers serve as helpers in the construction of a context of coexistence and real and verifiable inclusion, which is a lifelong learning for all.

Furthermore, it is a must to put into practice strategies for sustainability based on the complex reality worked qualitatively: tutoring, technical training, proximity to technologies, understanding of issues such as harassment, bullying, and school dropout.

We are part of a globalized world that is reflected in problems associated with the development of the various dimensions of human endeavor. Countries are classified, in terms of market values, in emerging, developed, and frontier. However, in educational matters, all have similar circumstances that can produce scenarios of discrimination, bullying or other types of aggressive practices. All this is confirmed by the intellectuals and scientists who explain the complexity of the 21 st century.

As a result, it is crucial to generate educational practices based on moral culture. Ethics and understanding the complexity of human life is the ultimate goal. To this end, it is fundamental that the teacher as a helmsman should learn how to maneuver in turbulent waters, as well as understand that the best way to arrive at a good port is, first of all, to listen to all the participants in order to incorporate resources that strengthen values towards a sustainable way of living in this complex reality.

According to this proposal, it is imperative that teachers should become the strategists of education that lead to the great challenges of our 21st century global society. Work must be done to remember this affirmation as well as to provide practical strategies for school activities that work to transform the environment into pathways to a future in which sustainability is the reflection of human beings' awareness of their participation as responsible citizens of the Earth.

\section{References:}

Amato, P. (2003). Making it happen: From interactvie to participatory language teaching. (3rd ed.). New York: Longman.

Bauman, Z. (2007). Los retos de la educación en la modernidad líquida. México: Gedisa. 
Cristison, M. A. \& Bassano, S. (1995). Look who's talking: Strategies for developing group interaction (pp. viii-ix). San Francisco, CA: Alta Book. Chomsky, N. (2001). La (des)Educación. Barcelona: Crítica.

Morin, E. (1999). Seven complex lessons in education for the future. París: UNESCO.

Morin, E. (2002). La cabeza bien puesta. Repensar la reforma. Reformar el pensamiento. Buenos Aires: Ediciones Nueva Visión.

Morin, E. (2011). La Vía para el futuro de la humanidad. España: Paidós. Morin, E. (2014). “A educação não pode ignorar a curiosidade das crianças'. Andrea Rangel entrevista a Edgar Morin. En https://oglobo.globo.com/sociedade/educacao/educacao-360/a-educacao-naopode-ignorar-curiosidade-das-criancas-diz-edgar-morin-13631748

Puig, J. (2011). "La cultura moral como sistema de prácticas y mundo de valores". XII Congreso Internacional de Teoría de la Educación. En http://www.cite2011.com/Comunicaciones/Escuela/003.pdf

Richards, J. C., \& Lockhart, C. (1994). Interaction in the second language classroom. In Reflective teaching in second language classrooms (pp. 138160). Cambridge, England: Cambridge University Press.

Santos, B. (2015). La universidad en el siglo XXI. México: Siglo XXI Editores.

United Nations (1987). Report of the World Commission on Environment and Development: Our Common Future. http://www.un-documents.net/ourcommon-future.pdf

United Nations (2015). Sustainable Development Goals. http://www.un.org/sustainabledevelopment/es/education/. 